\title{
LA POESÍA BURLESCA DEL SIGLO DE ORO Y SUS MODELOS ITALIANOS
}

En el Siglo de Oro se cultivaron dos géneros que la tradición italiana condicionó y que tienen varios puntos en común: la poesía satírica y la poesía burlescal ${ }^{1}$ Los criterios empleados para distinguirlas no han sido uniformes y han dado como resultado diferentes teorías a veces complementarias, basadas sobre todo en cuestiones de tipo ideológico, estilístico y formal ${ }^{2}$. El problema se agrava al constatar que los preceptistas del Siglo de Oro español suelen hacer caso omiso de la lírica festiva en sus poéticas y retóricas, ya que esta modalidad no constaba como tal en el canon clásico greco-romano. El objetivo de este trabajo es, pues, estudiar el desarrollo de la poesía burlesca en España, prestando especial atención a la influencia que ejerció sobre ella la literatura italiana.

El vacío teórico sobre la poesía burlesca durante el siglo xvr contrasta con la importante sistematización por la que pasó uno de sus elementos constituyentes más importantes: la risa. Sus manifestaciones son tan antiguas como el hombre y su estudio parte, por lo menos, del mundo clásico. No sería, pues, del

1 Por lo que respecta a la sátira, véase mi trabajo "La poesía satírica en el Siglo de Oro: el modelo ariostesco", BHS, 81 (2004), en prensa.

2 Véanse, R. Jammes, La obra poética de don Luis de Góngora y Argote, trad. M. Moya, Castalia, Madrid, 1987, pp. 31-38; I. Arellano, Poesia satírico burlesca de Quevedo, Eunsa, Pamplona, 1984, pp. 22-38; W. Woodhouse, "Hacia una terminología coherente para la poesía satírica del Siglo de Oro", en Actas del VIII. Congreso Internacional de Hispanistas, eds. A. D. Kossoff et al., Istmo, Madrid, 1986, t. 2, pp. 749-753; A. PÉrez Lasheras, Fustigat mores. Hacia el concepto de la sátira en el siglo XvI, Universidad, Zaragoza, 1994, pp. 139-182, y su Más a lo moderno. (Sátira, burla y poesía en la época de Góngora), Anexos de Tropelias, Zaragoza, 1995, pp. 13-20.

NRFH, LI (2003), núm. 2, 465-491 
todo exacto afirmar que la teoría de la risa nació con el Renacimiento. Ya en el Medievo hubo tratados que se ocuparon de la cuestión ${ }^{3}$. Sin embargo, nunca como en el Renacimiento el hombre se preocupó por definir la naturaleza de lo ridículo y el papel que éste ha de jugar en la sociedad. La capacidad de suscitar la diversión y de disfrutar de ella es considerada, partiendo de la definición aristotélica, como una característica exclusivamente humana: "el hombre es el único de los animales que ríe" 4 . Por tanto, el individuo fino, cortés y bien educado ha de saber cultivar tanto los aspectos más graves de la vida como los meramente facetos.

La ideología renacentista atribuye una gran importancia al juego, a la fiesta y a la distracción. El hombre completo debe conjugar de igual manera el otium con el negotium. El ocio y la diversión, pues, tienen un lugar destacado en los tratados de la época que se ocupan de los buenos modales y del lenguaje más apto a los hombres de la aristocracia. A partir de Cicerón (De oratore, II, 216-340) y Quintiliano (VI, 3) ${ }^{5}$, la risa y su expresión verbal se codifican como uso social y cortesano. Tres son las obras fundamentales en el Renacimiento a este respecto: e]

3 J. S. P. TATLOCK, "Mediaeval laughter", Sp, 21 (1946), 289-294; H AdoLF, "On mediaeval laughter", Sp, 22 (1947), 251-253; E. R. Curtius, Lite ratura europea y Edad Media latina, trads. M. Frenk y A. Alatorre, F.C.E., Ma drid, 1976 (2a reimp.), t. 2, pp. 594-618; F. López Estrada, "Manifestacione: festivas de la literatura medieval castellana", en Formas carnavalescas en el ar te y la literatura, ed. J. Huerta Calvo, Ediciones del Serbal, Barcelona, 1989 pp. 63-117; P. MÉNARD, "Le rire et le sourire au Moyen Âge dans la littératurt et dans les arts. Essai de problématique", en Le rire au Moyen Âge dans la litté rature et dans les arts, eds. T. Bouché et $\mathrm{H}$. Charpentier, Presses Universitaire: de Bordeaux, Bordeaux, 1990, pp. 7-30; J. LE Goff, "La risa en la Edad Me dia", en Una historia cultural del humor. Desde la Antigüedad a nuestros días coords. J. Bremmer y H. Roodenburg, Sequitur, Madrid, 1999, pp. 41-54.

4 Aristóteles, Partes de los animales, trads. E. Jiménez y A. Alonso, Gre dos, Madrid, 2000, 673a. Sobre la importancia de la sentencia aristotélica eı el Renacimiento véase M. BAjTín, La cultura popular en la Edad Media y en c Renacimiento. El contexto de François Rabelais, trads. J. Forcat y C. Conroy Alianza, Madrid, 1998 (reimp.), pp. 66-67; y D. MÉnAger, La Renaissance et rire, PUF, Paris, 1995, pp. 12-17.

${ }^{5}$ En general, las retóricas consideran la risa como un medio muy úti para conquistar el favor del auditorio y el saber suscitarla como una cual dad propia del buen orador: Cicerón, De oratore, II, 340; Orator, 138; Brutu: 143, 158 y 322; Rhetorica ad Herennium, I, 10. Para una visión de conjunto sc bre las teorías antiguas sobre la risa véase M. A. GRANT, The ancient rhetoric theories of the laughable. The Greek rhetoricians and Cicero, University of Wiscor sin, Madison, 1924. 
De sermone (1509) de Giovanni Pontano, el Cortegiano (1528) de Castiglione y el Galateo (1558) de Giovanni Della Casa. Incluso se escribieron estudios específicos sobre el tema, como el De ridiculis (1550) de Vincenzo Maggi. Estos libros dedican amplio espacio al análisis y definición de los tipos de facecias, de la risa y de los mejores métodos para obtenerla ${ }^{6}$.

La risa ha de consistir, según Pontano, en una "recreationem post labores"7; idea que depende, nuevamente, de Aristóteles: "la diversión es una especie de descanso, y como los hombres no pueden trabajar continuamente, tienen necesidad de descanso" $"$. La risa es, pues, una distracción propia del hombre, que depende de su inteligencia y que, de ser empleada correctamente, puede demostrar una cultura refinada.

En España también se introdujo esta concepción positiva de la risa y de la burla. A partir del siglo xvi se fue estableciendo cada vez con mayor intensidad la práctica del "motejar" en los ambientes sociales más selectos ${ }^{9}$. A principios del siglo XVII empiezan a circular en España varias obras que llevan el marbete de "burlescas": comedias y poemas, sobre todo. Estrechamente emparentadas con él, se pueden encontrar también palabras como "jocoso", "faceto", "festivo" o "gracioso"10. El término "burlesco", casi seguramente, vino de Italia, donde se empleaba por lo menos desde el siglo Xvi ${ }^{11}$. Su mayor difusión se debe

${ }^{6}$ M. J. Vega Ramos, "De ridiculis. La teoría de lo ridículo en la poética del siglo xv", en Humanismo y pervivencia del Mundo Clásico I, coords. J. M. Maestre y J. Pascual, Instituto de Estudios Turolenses-Universidad de Cádiz, Cádiz, 1993, t. 2, pp. 1107-1118; y J. C. Pueo, "De Cicerón a Pontano: la adaptación renacentista de la teoría retórica de la risa", en Actas del Congreso Internacional sobre Humanismo y Renacimiento, coords. J. Matas et al, Universidad, León, 1998, t. 2, pp. 573-580.

${ }^{7}$ De sermone, eds. S. Lupi y A. Risicato, Thesauri Mundi, Lugano, 1954, 1, 12.

${ }^{8}$ Ética a Nicómaco, eds. y trads. M. Araujo y J. Marías, IEP, Madrid, 1959, $1176 \mathrm{~b}$.

${ }^{9}$ Las formas de la agudeza relacionadas con el motejar en el Siglo de Oro español se detallan en los trabajos de M. Chevalier, "Le gentilhomme et le galant. À propos de Quevedo et de Lope”, $B H i, 88$ (1986), 5-46; y Quevedo y su tiempo: la agudeza verbal, Crítica, Barcelona, 1992.

${ }^{10}$ Véanse, K. ConTaG, Mockery in Spanish Golden Age literature. Analysis of burlesque representation, University Press of America, Lanham-New York-London, 1996; M. Joly, La bourle et son interprétation. Recherches sur le passage de la facetie au roman. (Espagne, $X V T^{e}$-XVII siècles), Université de Lille III, Lille, 1986.

${ }^{11}$ M. Morreale, Castiglione y Boscán: el ideal cortesano en el Renacimiento español, Anejo I del Boletin de la Real Academia Española, Madrid, 1959, t. 1, p. 217; y M. Joly, $o p$. cit., p. 23. 
al florecimiento de la poesía de Francesco Berni (1497 o 14981535) y de sus seguidores, los bernescos. Este corpus de textos se publicó mayoritariamente en antologías que, desde 1537, conocieron un gran número de ediciones. Lo más habitual es que llevaran en su título el adjetivo piacevole o burlesco, que en Italia terminó por asociarse normalmente con este tipo de poemas. La primera edición en la que se emplea el término "burlesco" es la de 1548, cuidada por Anton Francesco Grazzini (il Lasca): Il primo libro dell'opere burlesche di M. F. Berni, di M. Gio. de lla Casa, del Varchi, del Mauro, di M. Bino, del Molza, del Dolce, E del Firenzuola. Berni aparece como la cabeza de un grupo com. pacto de poetas que se califican a sí mismos de "burlescos" ) "bernescos" (no olvidemos que también Grazzini cultivó la poe. sía bernesca). La fortuna editorial de estas antologías fue enor me durante todo el siglo xvi y el xvt, y debieron alcanzar ur éxito considerable también en España. Precisamente a parti de estas obras hay que buscar el origen del término "burlesco' en la literatura española ${ }^{12}$. Así lo demuestra, por ejemplo, Lo pe de Vega en una carta de 1611 dirigida al Duque de Sessa, er la que asocia este marbete con la tradición italiana: "uno de lo: estilos del formulario italiano se llama burlesco"13.

Una de las primeras muestras de la paulatina introducció del marbete "burlesco" en la poesía española la proporcion: Juan de la Cueva en la dedicatoria de sus rimas firmada er 1603 (permanecieron manuscritas):

Dispuesto ya de dar mi flaca vela a su inmoderada soberbia,junt de mis papeles ese volumen...; hice división dél en dos partes: el la primera puse todas las rimas sueltas, mezclando con la varic dad de sujetos las composiciones amatorias, misivas y burlescas por variar los gustos a los lectores ${ }^{14}$.

Otro ejemplo aún más importante del uso del adjetivo "bu leseo" se encuentra en la obra de Góngora. En sus tercetos d

12 K. Contag, op. cit., p. 44. F. Plata, "Contribución al estudio de la fuentes de la poesía satírica de Quevedo: Ateneo, Berni y Owen”, La Perin la, 3 (1999), p. 237 da noticia del testimonio más antiguo documentado d. término 'burlesco' en la literatura española. Lope de Vega emplea el adjeı vo en La bella malmaridada (v. 151), comedia de la que se conserva una cop: manuscrita con fecha de 17 de noviembre de 1596.

${ }^{13}$ Lope de VeGa, Cartas, ed. N. Marín, Castalia, Madrid, 1985, p. 83.

14 En B. J. Gallardo, Ensayo de una biblioteca española de libros raros y cum sos, ed. facs., Gredos, Madrid, 1968, t. 2, col. 655. 
1609 ":Mal haya el que en señores idolatra" distingue entre poetas que "o burlescos sean o graves" (v. 24) ${ }^{15}$, y en el Manuscrito Chacón (1628) hay un gran número de poemas que llevan el marbete de "burlescos". Su compilador, Antonio Chacón, sin embargo, se siente todavía en la obligación de justificar este término, que se percibe como ajeno a la lengua castellana:

El nombre que se da de Burlescas à las que lo son, va (como lo demas) expuesto à las censuras de los que, por Latino, quiçà admitieran menos el de iocosas. Pero ni nuestra lengua tiene otro adjetivo desta significacion, ni Don LVIS estrañò este en los exemplares que permitiò de sus Obras ${ }^{16}$.

El rótulo "burlesco" pasó también a las primeras ediciones impresas que se hicieron del poeta cordobés. Su empleo quedaba fijado y aparecería en otras obras de la época. Pero, más allá de las cuestiones terminológicas, es importante conocer hasta qué punto los escritores italianos influyeron en los españoles. Para ello, es preciso empezar delimitando las fronteras históricas y genéricas que separan la poesía burlesca de la satírica, que a menudo suelen confundirse. El iniciador de la sátira moderna en verso en Italia fue Ludovico Ariosto, quien siguiendo el ejemplo de Horacio escribió unos tercetos epistolares de tono medio y familiar titulados Satire ${ }^{17}$. Este cauce guarda ciertos parecidos con la tradición bernesca, aunque los lectores de los siglos Xvı y xvII las identificaban como géneros diferentes.

La poesía burlesca se caracteriza, fundamentalmente, por el contenido jocoso, la desmitificación y parodia de los códigos altos (poesía petrarquista, épica, encomiástica), el estilo bajo y frecuentemente vulgar. Su finalidad básica es la de causar la risa, la de entretener al lector. Sin embargo, no es infrecuente que en sus versos se hallen implícitos mensajes propios del modelo satírico: la censura de vicios, el desprestigio de los falsos valores de la sociedad, la ridiculización de los pecadores. Estos paralelismos han originado muchos problemas a la hora de in-

15 Luis de Góngora, Canciones y otros poemas en arte mayor, ed. J. M. Micó, Espasa-Calpe, Madrid, 1990, p. 267.

16 En Obras de don Luis de Góngora. [Manuscrito Chacón], ed. facs., RAECaja de Ahorros de Ronda, Málaga, 1991, 3 ts.

17 Acerca del modelo satírico ariostesco y su fortuna véase P. Floriani, Il modello ariostesco. La satira classicistica nel Cinquecento, Bulzoni, Roma, 1988. 
tentar sistematizar el corpus satírico y el burlesco, llegando a mezclarse con facilidad ambos conceptos. Entre las varias características que comparten y que dificultan su distinción, la más importante es la risa. La poesía burlesca entiende la diversión como un "reírse de", atacar - ya sea en juego ya en serio-a alguien o algo. En esto coincide con la sátira, que suele expresar su repulsa hacia algo por medio de la invectiva. Pero ello se debe a que la risa, en su expresión más general, consiste precisamente en eso: reconocer el ridículo en lo ajeno y gozar con su percepción ${ }^{18}$. Poesía satírica y burlesca comparten también algunos rasgos estilísticos semejantes, con una clara presencia en ambas del genus humile (aunque en la sátira no se desdeñan tampoco modalidades más elevadas). Además, las dos formas permiten la combinación de una amplia gama de argumentos bajos y humildes. En Italia, para mayor complicación, ambas modalidades emplean una misma forma métrica: la terza rima Sin contar el importante número de capitoli bernescos escrito: en forma epistolar, cauce fundamental de la sátira ariostesca ${ }^{19}$

Sin embargo, existen diferencias básicas entre poesía bur lesea y satírica tal y como se practicaron en Italia, que resider en sus finalidades y en su estilo. El objetivo principal de la sátir: es la moralización, que se puede obtener por medio de la risa de la invectiva. La poesía burlesca, en cambio, busca sobre todi causar la risa a través del juego verbal ingenioso. Evidentemente entre sus contenidos puede tener larga cabida la moralización pero será casi siempre un elemento secundario con respecto su meta final.

La poesía burlesca, además, se fundamenta en unos prest puestos estilísticos diferentes a los de la sátira. No busca la re presentación de lo cotidiano y lo humilde, basándose en $t$ ideal horaciano de aura mediocritas, sino la deformación hipe: bólica del objeto retratado. La importancia de la hipérbole y d

18 J. Ritter, Subjetividad. Seis ensayos, trad. R. de la Vega, Alfa, Barcelon 1986, p. 55; y V. Propr, Comicità e riso. Letteratura e vita quotidiana, trad. ( Gandolfo, Einaudi, Torino, 1988, p. 16. En general, todas las teorías sob] la risa destacan su faceta destructora y agresiva a expensas ajenas. Véanse, Freud, El chiste y su relación con lo inconsciente, en Obras completas, trad. L. L pez, Biblioteca Nueva, Madrid, 1967, t. 1, pp. 825-937; y H. Bergson, Il ri: trads. A. Cervesato y C. Galio, Laterza, Roma-Bari, 1996².

19 Sobre los capítulos bernescos escritos en forma de epístola véa S. Longhi, Lusus. Il capitolo burlesco nel Cinquecento, Antenore, Padova, 198 pp. 182-209. 
la metáfora es mucho mayor que en la sátira. Ello da pie al juego lingüístico y a la experimentación verbal, elementos que aparecen casi siempre en un segundo plano en las sátiras clasicistas. Frente a la contención del satírico, el autor burlesco persigue el exceso cómico. De todas formas, es preciso reconocer que no siempre es fácil establecer una neta separación entre el género burlesco y el satírico. En Italia también se percibió esa cercanía y se intentó contrarrestarla a través de las antologías poéticas.

El contexto poético y material, el espacio cerrado del libro es muy útil a la hora de estudiar fenómenos literarios. Una obra que aislada puede entrañar dificultades de definición genérica, encuentra una caracterización más nítida al incluirse en un conjunto de obras gemelas que la justifican. Como recuerda Curtius: "De las literaturas modernas, fue la italiana la primera que forjó un canon" 20 . Este proceso se obtuvo a partir del Humanismo con el redescubrimiento de los géneros clásicos. Las formas antiguas se editaban, anotaban y estudiaban. Dentro de esta tarea, desempeñaron un papel fundamental las antologías donde se recogían estas obras atendiendo a su molde genérico. Las grandes imprentas del Renacimiento, como la de Manuzio y la de Estienne, publicaron colecciones de poetas heroicos griegos o de filósofos, entre otros ${ }^{21}$. En 1481 se editan en Florencia las Bucoliche elegantissimamente composte de varios autores que contribuyen decisivamente a reinstaurar el modelo bucólico en la literatura italiana. En todo el siglo xvi, las antologías "genéricas" van a ser muy abundantes y resultarán fundamentales en el proceso de fijación del canon literario. La variedad es muy grande: Lettere di diversi eccellentissimi uomini; De le lettere facete et piacevoli di diversi grandi huomini; Tutti i trionfi, charri, mascherate o canti Carnascialeschi; Prima parte delle stanze di diversi illustri poeti; Rime di diversi antichi autori; Il primo volume delle rime scelte di diversi autori; Diverse orationi scritte da huomini illustri; Rime di diversi eccel. autori in morte della illustriss. sig. D. Hippolita Gonzaga; Cento novelle scelte da' piu nobili scrittori della lingua volgare; Rime diverse d'alcune nobilissime, virtuosissime donne. Estos volúmenes ofrecían a un público más amplio la posibilidad de acceder a modelos literarios ya codificados y aptos para

${ }^{20}$ Curtius, op. cit., t. 1, p. 372.

${ }^{21}$ R. L. COLIE, The resources of kind. Genre-theory in the Renaissance, University of California Press, Berkeley-Los Angeles-London, 1973, pp. 15-16. 
ser imitados y generar nuevas composiciones ${ }^{22}$. El cauce imitativo propio de los siglos xvı y xvII encontraba así un apoyo rico y variado. Editores y compiladores como Doni, Sansovino, Domenichi, Dolce y el mismo Grazzini fueron los artífices materiales de este proceso de difusión.

No cabe ninguna duda de que la fortuna de un movimiento como el petrarquista, por ejemplo, debe mucho a estas antologías. A partir de 1545, fecha en que se publicó el Libro primo del le rime, la poesía amorosa se extiende fuera y dentro del país. La entrada en España de estas colecciones de versos fue constant $\epsilon$ y amplia, contribuyendo de forma decisiva al triunfo de este modalidad en el ámbito hispano ${ }^{23}$. Lo mismo se puede decis por lo que respecta a la poesía satírica y burlesca.

En Italia, la respuesta ante los problemas de confusión ori ginados por los modelos satírico y burlesco también llegó a tra vés de las antologías. Tras la publicación de las sátiras dı Ariosto (1534) y de las rimas de Berni (1537), muchos autore se cimentaron en ambos géneros. Los puntos de contacto entrı ellos hicieron que a mediados del siglo xvi se imprimieran algu nas obras donde las dos poéticas parecían confluir en un únicr cauce. Pero en 1560 y 1565 se editaron dos antologías de sátira recogidas por Francesco Sansovino y Mario degli Andini, qu operaron una rígida selección de textos, descartando los poc mas de carácter más burlesco y tomando como patrón las sát ras de Ariosto ${ }^{24}$. En la antología preparada por Mario deg Andini se incluye el discurso Sovra la materia della satira de Li dovico Paterno, que deja zanjada la cuestión rechazando abie: tamente la asimilación de la poesía burlesca con la satírica:

22 R. FEDI, La memoria della poesia. Canzonieri, lirici e libri di rime nel Rinas mento, Salerno Editrice, Roma, 1990, pp. 23-51.

${ }^{23}$ M. P. Manero Sorolla, "Antologías poéticas italianas de la segunc mitad del siglo xvi (1545-1590)", Anuario de Filología, 1983, núm. 9, 259-29 Para la importancia de las antologías poéticas italianas en España véase 1 L. Cerrón Puga, "Las antologías de poesía italiana en la Biblioteca Nacion de Madrid (1532-1637)", Edad de Oro, 12 (1993), 41-60.

${ }^{24}$ F. Sansovino (ed.), Sette libri di satire di Lodovico Ariosto. Hercole Bentiz gli. Luigi Alamanni. Pietro Nelli. Antonio Vinciguerra. Francesco Sansovino. d'altri scrittori. Con un discorso in materia della Satira, Francesco Sansovino, V netia, 1560; M. DEGLi ANDINI (ed.), Satire di cinque poeti illustri, di nvovo racce et poste a lvce, Gio. Andrea Valvassori, Venetia, 1565. Acerca del impacto : estas dos antologías véanse, P. Floriani, op. cit, pp. 7 y 185-189; y A. CorSAr La regola e la licenza. Studi sulla poesia satirica e burlesca fra Cinque e Seicen Vecchiarelli, Manziana, 1999, pp. 49-55. 
Non entro ne'leggiadri, \& festosi capitoli del Casa, del Bernia, \& de' compagni. Percioche tutto che nelle sue case, per dir così, paiano assai belli, \& ammirandi: nondimeno quando escono fuori à fronte delle Satire, s'accattano gran disaguaglianza appresso i circostanti, facendo quella uista, che la magnificenza delle padrone suol fare alla bassezza delle seruenti ${ }^{25}$.

La sátira es un género noble de ascendencia clásica, pese a su estilo medio-bajo y a sus contenidos a veces cotidianos. La poesía bernesca, en cambio, tiene una tradición meramente vulgar y no alcanza la distinción de la poesia satirica. Para Paterno, comparadas se parecen a las criadas frente a las señoras. Estas dos antologías gozaron de mucha difusión, sobre todo la de Sansovino que conoció varias reediciones. Por otra parte, las colecciones de versos bernescos contribuían a instaurar su modelo al margen de la literatura satírica.

También en los prólogos de algunas antologías bernescas del siglo xvi se intenta definir la naturaleza de la poesia burlesca y diferenciarla de la sátira. Por ejemplo, en los preliminares de la edición del Secondo libro dell'opere burlesche (1555) costeada por él, Filippo Giunti deja muy clara la distancia entre ambos géneros. De las dos finalidades de la poesía, entretener y enseñar, la poesía burlesca persigue la primera y la satírica la segunda. Entre los autores festivos destaca Francesco Berni, "primero" y maestro de los burlescos:

Tvtti i Poeti hanno per intentione l'uno de due fini, come V. S. sà molto meglio di me, cioè o di giouare, o di dilettar le persone... Gli scrittori delle Satire, quasi arbitri del mondo, senza risguardo hauer ne a Principi ne a priuati huomini, ma di tutti, indifferentemente, i vitii biasimando, si sforzano di mettere altrui sulla via della virtù. Altri Poeti poi, come ho detto, ci sono, che altro non disegnano se non recar piacere \& diletto alle genti... Di questa maniera di faceti \& sollazeuoli Scrittori \& Poeti molti \& molto eccellenti n'hà hauuto, \& ha tuttauia il secol nostro; il qual (dirò liberamente) non cede in cosa alcuna all'antico. Et fra primi, \& forse il primo, che in tal maniera di scriuere in burla lodeuolmente poetasse, fù il nostro Messer Francesco Berni ${ }^{26}$.

${ }^{25} \mathrm{En}$ Satire di cinque poeti illusiri, ff. A5v-A6.

${ }^{26}$ Il secondo libro dell'opere Burlesche, di M. Francesco Berni. Del Molza, di M. Bino, di M. Lodouico Martelli. Di Mattio Francesi, dell'Aretino, Et di diuersi Autori. Nuouamente posto in Luce, Et con diligenza Stampato, Heredi di Bernardo Giunti, Fiorenza, 1555, ff. †ii-†iiv. 
La figura central del desarrollo de la poesia burlesca en el Renacimiento fue, pues, Francesco Berni27. Sacerdote toscano nacido en Lamporecchio, trabajó al servicio de importantes señores relacionados con la curia, como el cardenal Bernardc Dovizi da Bibbiena, el datario Giovan Matteo Giberti y el cardena! Ippolito de' Medici. Su formación humanística le llevó inicial. mente a escribir poesía en latín, pero pronto pasó a cultivar la literatura burlesca. Berni supo aprovechar la tradición anterios y su cultura clásica para sus composiciones. La combinación de fuentes nacionales (Dante, Petrarca, Burchiello, Pistoia) y lati nas (Horacio, Virgilio, Catulo) le permitió dignificar la poesíc festiva y darle un nuevo empuje dentro de la cultura del Rena cimiento.

Los moldes métricos fundamentales de la poesía de Bern son el soneto y el terceto. En el primero toma los motivos tipi eos de la literatura cómica anterior (Burchiello, Pistoia), aun que su estructura responde más a la técnica petrarquista. $\mathrm{E}$ poeta supo combinar unos contenidos bajos con una forma a ta obteniendo un resultado original y novedoso ${ }^{28}$. Sin embai go, la parte más amplia de su repertorio la constituyen lc capitoli que pasarían a ser el metro básico de la poesía bernesca Los temas de la obra de Berni se centran en la parodia del pr trarquismo, el retrato de tipos y escenas grotescas y, sobre todc el elogio paradójico. El poeta toscano partió de una modalida clásica que estaba conociendo mucho éxito en el Renacimier to (pensemos en el Elogio de la locura de Erasmo) y la fusion con la tradición florentina de los Canti camascialeschi. Se trata c una forma de origen popular que cultivaron también autor cultos de los siglos xv y xvl como Lorenzo de' Medici o Ben detto Varchi ${ }^{29}$. Estos poemas eran escenificados por compars: que subidas en carros atravesaban las calles de Florencia en lc

27 Para una visión de conjunto sobre Berni y los bernescos consúlten D. RoMeI, Berni e berneschi del Cinquecento, Edizioni Centro 2P, Firenze, $19 £$ S. LongHI, "Le Rime di Francesco Berni. Cronologia e strutture del lingua gio burlesco", Studi di Filologia Italiana, 1976, núm. 34, 249-299; y su Lusu: 28 G. Bernard, "Le sonnet bernesque", en Le sonnet à la Renaissance: origines au Xvir siècle, ed. Y. Bellenger, Aux Amateurs de Livres, Paris, $19 £$ pp. 195-204.

${ }^{29}$ G. FERroni, "Il doppio senso erotico nei canti carnascialeschi fiorentir Sigma, 11 (1978), núms. 2/3, 233-250. Anton Francesco Grazzini recogió $\mathrm{n}$ chos de estos textos y los publicó en 1559: Tutti i trionfi, carri, mascherate o ca carnascialeschi. 
días de carnaval. Normalmente, representaban la llegada a la ciudad de un grupo de personajes que encarnan una profesión, actividad o estamento (sastres, herreros, monjas, viudas), y que entablan un diálogo ficticio con su destinatario basado en las metáforas y dobles sentidos eróticos. Su enunciado es muy sencillo y esquemático, y la doble lectura que encubren muy evidente. Siguiendo estos dos modelos, los tercetos de Berni loan cosas humildes (melones, melocotones, gelatina) o perniciosas (la peste), jugando con un doble nivel de lectura que encubre un significado sexual. Cito como ejemplo el capítulo de las anguilas:

L'anguille non son troppo conosciute;

E sarebbon chiamate un nuovo pesce

Da un che noll'avesse più vedute.

Vivace bestia che nell'acqua cresce,

$E$ vive in terra e 'n acqua, e 'n acqua e 'n terra,

Entra a sua posta ov'ella vuole, ed esce ${ }^{30}$.

La anguila tiene un claro valor fálico y las referencias a la "tierra" y al "agua" aluden, respectivamente, al amor sodomitico y al heterosexual. Este lenguaje basado en el ingenio y el equívoco fue imitado muy pronto ${ }^{31}$. La poesía bernesca se desarrolló inicialmente en Roma, alrededor de un grupo de escritores amigos del poeta que en sus reuniones académicas se entretenían componiendo capítulos burlescos. En realidad, poco se sabe de esta agrupación que se conoce con el nombre genérico de Accademia dei vignaiuoli32. Desconocemos si en algún momento llegó a funcionar realmente como academia o no pasó de ser una reunión entre amigos. Los miembros más destacados de esta sociedad de escritores jocosos son, junto con Berni, Giovanni Mauro (muerto en 1536), Giovanni Della Casa

30 F. Berni, Rime, ed. S. Longhi, en Poeti del Cinquecento, t. 1: Poeti lirici, burleschi, satirici e didascalici, eds. G. Gorni, M. Danzi y S. Longhi, Ricciardi, Milano-Napoli, 2001, pp. 623-890, 5, wv. 10-15.

$31 \mathrm{~J}$. Toscan ha estudiado el léxico de la tradición bernesca, desvelando sus dobles sentidos obscenos en su libro Le carnaval du langage. Le lexique érotique des poètes de l'équivoque de Burchiello à Marino (XV'-XVII siècles), Presses Universitaires de Lille, Lille, 1981, 4 ts. Sin embargo, su labor de descodificación a menudo va demasiado lejos y halla referencias eróticas en pasajes donde son dudosas o improbables. Véanse las matizaciones de D. RoMEI, $o p$. cit., pp. 85-107; y P. FLORIANI, op. cit, pp. 191-196.

${ }^{32}$ D. Romer, op. cit., pp. 51-84. 
(1503-1556), Giovan Francesco Bini (muerto en 1556), Francesco Maria Molza (1489-1544), Annibal Caro (1507-1566), Agnolo Firenzuola (1493-1543) y Mattio Franzesi (muerto antes de 1555). Se trata de un grupo bastante homogéneo de intelectuales de formación humanística, relacionados con la curia (algunos eran sacerdotes) y varios de ellos de origen toscano. En sus versos cantan objetos insignificantes o viles, tales como las zanahorias, los huevos, la ensalada, el barro, la salchicha, las mentiras o las ventas.

Estos capitoli burlescos conocieron una gran fortuna, y muchos autores escribieron tercetos "in lode" o "in dispregio" al estilo de Berni. Girolamo Ruscelli, quien también compusc poemas bernescos, dejó constancia de este éxito en su tratadc Del modo di comporre in versi nella lingua italiana (1559), donde $s \epsilon$ queja por la degeneración de la poesia bernesca en moda li. teraria:

per Paradosso è quella del Bernia che loda la peste, del Molza che lodò la scommunica, \& altri tali. Et de' soggetti umilissimi lo dati altamente ò da scherzo sono quei de' Cardi, et dell'Insalata del Forno, dell'Ago, del Fuso, \& molti altri, che ne uanno attorn gioiosamente, \& molto vaghi, \& molto grati, se non che s'è po posta in fascio molta turba à uolerui scriuere, ò bene, ò male, chı sappia farlo ${ }^{33}$.

La fortuna de los capitoli bernescos se aprecia en la gran di fusión de las antologías de poesía burlesca que, desde 1537, sı editaron sin cesar. Como ya ocurriera con Ariosto en las recopi laciones satíricas de Francesco Sansovino y Mario degli Andinj Berni solía encabezar las antologías burlescas tomando el pape de fundador y maestro del género. Así lo hizo Filippo Giunti es el Secondo libro dell'opere burlesche. Pero ya antes Anton Francesc Grazzini lo había dejado muy claro en su edición de las $O p e$ burlesche de 1548. En los preliminares del libro incluye un sont to suyo donde alaba a Berni y lo considera el padre del estil burlesco: "maestro e padre del burlesco stile" 34 .

La antología del Lasca y su segunda parte fueron dos de lc más difundidas en el siglo xvI (reeditadas varias veces) y sobr

33 Del modo di comporre in versi nella lingua italiana, Giovan Battista et M€ chior Sessa Fratelli, Venetia, 1559, p. cxvi.

34 A. F. Grazzini, Le rime burlesche edite e inedite, ed. C. Verzone, Sansor Firenze, 1882, soneto 98, v. 8 . 
ellas se basaron la mayoría de las que se publicaron en el siglo XVII. Es el caso de la edición dividida en tres libros Delle rime piacevoli..., Barezzo Barezzi, Vicenza, 1603 (reeditada de nuevo en Vicenza en 1609-1610 por Francesco Grossi) ${ }^{35}$. Otra tradición afortunada fue la de las rimas de Cesare Caporali (1531-1601), que a partir de 1586 se reeditaron conjuntamente con las de otros bernescos.

En el siglo XVII, pues, se siguieron publicando antologías de poesía bernesca, aunque se trata de textos bastante defectuosos, con muchos problemas de atribución y lecturas equivocadas. Además, en la mayoría de los casos los versos más irreverentes fueron censurados. La huella del Concilio de Trento se dejó ver también en la circulación de la lírica burlesca. Sin embargo, ello no impidió que varios epígonos de Berni vieran impresas sus obras en el Barroco. Pensemos en autores como Alessandro Allegri (1550-1620), Girolamo Leopardi que publicó sus Capitoli e canzoni piacevoli en 1613, o Giovan Battista Lalli que incluyó sus Rime giocose en la primera edición de la Franceide (1629) y posteriormente en sus Opere poetiche $(1630)^{36}$.

Las obras cómicas italianas y las antologías de la poesía bernesca tuvieron que empezar a circular en España relativamente pronto. El modelo proporcionado por los burlescos italianos resultó muy sugestivo para los poetas españoles. De hecho, Francesco Berni es citado con mucha frecuencia como ejemplo fundamental de la poesía jocosa. Juan de la Cueva lo menciona en este sentido, junto con Aretino, en una de sus epístolas:

Y al poeta melado o Melosino

De indigestos concetos, qu'es entr'ellos, Bernia en donaire, en mofas Aretino ${ }^{37}$.

El escritor andaluz hizo referencia a Berni también en su obra más teórica: el Exemplar poético (escrito alrededor de 1605). Al hablar del soneto con estrambote y de su introduc-

35 En la colección aparecen también autores nuevos de finales del siglo xvi. Esta serie se reeditó con el añadido de una cuarta parte de rimas burlescas: Delle rime piacevoli..., Francesco Baba, Venetia, 1627.

36 Las Rime piacevoli de Allegri se publicaron en cuatro partes (1605, $1607,1608$ y 1613$)$. Sobre la pervivencia de la poesía burlesca a finales del siglo xvi y en el xvir véase C. CHIodo, Il gioco verbale. Studi sulla rimeria satiricogiocosa del Seicento, Bulzoni, Roma, 1990.

${ }^{37}$ En B. J. Gallardo, op. cit., t. 2, col. 695. 
ción en la poesía española, lo presenta como una deuda con la literatura italiana, más concretamente con Berni. Pese al rechazo que le supone esta forma métrica, es bastante significativa la mención del poeta italiano como modelo de poesíajocosa:

i cuando en esto alguna vez ecede i aumenta versos, es en el burlesco, qu'en otros ni aun burlando se concede.

Esto usó con donayre truhanesco el Bernia i por su exemplo á sido usado este épodo o cola que aborresco ${ }^{38}$.

También Góngora cita a Berni en uno de sus romances bur lescos: "Hanme dicho, hermanas" (de 1587). La alusión no e: casual. Esta composición del poeta cordobés es el primer ejem plo de "autorretrato burlesco" en la lírica española, modalidac que después utilizarían varios escritores. Góngora debió toma el modelo de la poesía bernesca donde se encuentran notable ejemplos, como los tercetos que se cruzaron Iacopo Sellaio : Mattio Franzesi ${ }^{39}$ :

porque son (y es cierto, que el Bernia lo afirma)

hermanas de leche nuevas y mentiras ${ }^{40}$.

La referencia es algo imprecisa. En varios lugares de su obras Berni mostró desinterés y desconfianza hacia las "nut vas", pero no encuentro ningún pasaje que se corresponda cor el del romance gongorino ${ }^{41}$. Lo importante es que Góngor certifica su deuda con la tradición bernesca italiana en un r $\epsilon$ manee que se inspira claramente en ella.

Luis Barahona de Soto dejó en uno de sus poemas otro in portante testimonio de la influencia de la literatura burlesc italiana en los autores del Siglo de Oro español. La epístola st gunda dirigida a Gregorio Silvestre ataca la mala poesía y st

38 Exemplar poético, ed.J. M. Reyes Cano, Alfar, Sevilla, 1986, vv. 1230-123.

39 Sobre estos poemas véase LongHi, Lusus, pp. 113-137.

40 Romances, ed. A. Carreño, Cátedra, Madrid, 20005, 24, vv. 149-152.

${ }^{41}$ En el capítulo "In lode del debito" (Rime, 26, wv. 175-190), en una de sI Lettere (en Poesie e prose, ed. E. Chiòrboli, Olschki, Genève-Firenze, 1934, p. 31 \& y en su Rifacimento del Orlando innamorato de Boiardo (III, 7, w. 54-55). 
defectos. En los versos centrales refiere una curiosa anécdota donde cuenta cómo un poeta es expulsado del jardín de las musas por su maledicencia, pese a lo cual consigue colarse dentro, pero es descubierto por las musas que quieren echarlo. Sin embargo, logra ganarse su benevolencia con zalamerías y éstas terminan entregándole las llaves del jardín:

Las llaves le entregaron del cerrado

Pitonio muro y de la ilustre fuente,

De que al principio tuvo tal cuidado.

Mas como puesto en posesión se siente

Del uno y otro venturoso cargo,

Y que a su intento la ocasión no miente,

Dicen, y aun es verdad, que, sin embargo,

Dio puerta general a mil iguales

Suyos en profesión, por tiempo largo.

Viendo la turba de moscones tales,

Mudaron el asiento a su Parnaso

Las nueve compañeras inmortales.

Quedaron sucesores en tal caso

Del huerto los sacrílegos profanos,

Que apenas para tantos bastó el vaso;

$Y$ ejercitaron el ingenio y $r$ anos,

Guál celebrando la virtud de un tronco;

Cuál cultivando el arbolaje y llanos.

Tal hubo que cantó del ajo bronco;

Tal de la dura y áspera alcarehofa

$\mathrm{Y}$ tal a quien un higo volvió ronco ${ }^{42}$.

Los poemas que componen estos poetas intrusos coinciden con los elogios paradójicos de los bernescos. El pasaje parece, pues, estar haciendo una crítica a la poesía burlesca italiana, como se confirmará versos más adelante. Pero además, la anécdota relatada por Barahona de Soto consiste en una larga paráfrasis en verso de un pasaje del Commento di ser Agresto da Ficaruolo sopra la Prima Ficata del padre Siceo (conocido también como la Ficheide), obra de Annibal Caro (alias "Agresto da Ficaruolo") publicada en 1539 junto con la Nasea ${ }^{43}$. El texto consis-

42 Poesias líricas, en F. Rodríguez Marín, Luis Barahona de Soto. Estudio biográfico, bibliográfico y critico, Real Academia Española, Madrid, 1903, pp. 581845 (pp. 709-710).

${ }^{43}$ Sobre estas obras de Caro véase G. Ferroni, "Lettere e scritti burleschi di Annibal Caro tra il 1532 e il 1542", Palatino. Rivista Romana di Cultura, 1968, núm. 12, 374-386. 
tía en un ejercicio académico donde Caro analizaba el Capitolo dei fichi de Francesco Maria Molza parodiando los comentarios eruditos, y siguiendo el modelo de Berni en su Comento al Capitolo della primiera. En las primeras páginas de su Ficheide el autor cuenta la historia que recoge Barahona de Soto en su epístola:

Fu il Bernia un certo uomo di messer Domenedio, il quale, con tutto che volesse essere Poeta rabbuffato dalle Muse, che non s'adattasse a scrivere, secondo che gli dettavano, s'abbottinò da loro, e disse tanto male d'esse, e de' Poeti, e della Poesia, che ebbe bando di Parnaso. Ma tosto che si avvide, che senza questa prati. ca era tenuto piuttosto per Giornea che per Bernia, si deliberò di rappattumarsi con esso loro. Ed appostando un giorno, che sta. vano nel medesimo giardino, fece tante moine intorno alle Ber. te, che son fantesche delle Muse, che si fece metter dentro per la siepe, e come quello ch'era il più dolce zugo del mondo, trovan dosi dentro, fece tante buffonerie, che le Muse ve lo lasciaronc stare. Dipoi s'ingegnò tanto, che rubò la chiave del cancello allí Madre Poesia lor Portinara; e misevi dentro una schiera d'altr Poeti baioni, che ruzzando per l'orto, lo sgominarono tutto, $c$ secondo che andarono loro a gusto, così colsero, e celebrarono chi le Pesche, chi le Fave, chi i Citriuoli, chi i Carciofi, e chi d'al tre sorti frutte ${ }^{44}$.

El texto de Caro, pese a su comicidad, consiste en un elogic a la poesía bernesca vista como obra de libertad frente a las re glas literarias. Berni supo desafiar a las musas y tuvo el mérite de abrir las puertas a una nueva concepción poética. Barahon: de Soto retomó este episodio para quejarse por el éxito excesi vo de los bernescos en España. Se trata de un testimonio mu explícito de la gran difusión de la poesía burlesca italiana en e Siglo de Oro:

Mas ya perdido este uso, se rehizo

Por un no sé qué Bernia italiano,

De donde fue en España advenedizo.

Del vándalo andaluz y castellano

Fue recebido con aplauso y pompa, Yaun muchos le trataron como a hermano ${ }^{45}$.

44 A. CAro, Commento di ser Agresto, G. Daelli e Comp. Editori, Milan 1863, p. 93.

${ }^{45}$ L. Barahona de Soto, Poesias líricas, p. 711. 
El poeta andaluz está utilizando un texto de literatura burlesca italiana para criticar esa misma tradición. Sin embargo, no está muy clara la postura de Barahona de Soto ante la obra bernesca, puesto que él mismo compuso unos tercetos de alabanza a la pobreza que guardan cierto parecido con poemas burlescos como el Capitolo sopra l'epiteto della povertà de Mattio Franzesi y el Capitolo a messer Gandolfo (sobre la carestia) de Giovanni Mauro. Quizás, como ya hiciera Ruscelli en su tratado poético, Barahona se esté quejando en su epístola de la trivialización de la materia bernesca y de su degeneración en moda literaria.

Un testimonio posterior que se mueve en la misma línea que el de Barahona se halla en el Rosal (compuesto entre 16231626) de Rodrigo Fernández de Ribera. Se trata de otro texto manuscrito donde el poeta andaluz recogió su poesía epigramática. En su discurso inicial, Ribera alaba a Marcial y lo considera el modelo fundamental que deben seguir los poetas jocosos españoles. La exaltación de la tradición nacional lo lleva a rechazar de lleno otras modalidades foráneas que "contaminaban" la poesía española:

¡Ó padre Marçial, emulaçión de los Catulos, Jubenales i Persios, i vosotros, ó hermanos poetas i hijos de aquél padre en este estilo! ¡Aquí del Pegaso, que si él fue buen cauallo español sería! Y sin duda que fue bueno, que a lo menos las alas esençia fueron del Zéfiro, de quien se enpreñaban las yeguas. Y de los prados del Betis, vosotros digo que ni alabáis en largos discursos el rábano mordaz, la lúgubre çebolla, ni el dulçe ygo, pero con la vrebe bala de una redondilla derribáis de desautorizada rissa la más mesurada muralla de una frunçida beata ${ }^{46}$.

Nuevamente, se puede apreciar el ataque directo a la poesía bernesca. Sin embargo, tanto las palabras de Barahona de Soto como las de Fernández de Ribera sirven para confirmar la importante presencia de la tradición burlesca italiana en España durante todo el Siglo de Oro. Es probable que su introducción se deba a Diego Hurtado de Mendoza. Su deuda con

${ }^{46}$ En J. Lara Garrido, "El Rosal, cancionero epigramático de Rodrigo Fernández de Ribera: edición y estudio del Ms. 17524 de la Biblioteca Nacional de Madrid (con algunos excursos sobre problemas de transmisión y edición de las poesías de Baltasar del Alcázar)", Voz y Letra, 3, 2 (1992), 2378; 4, 2 (1993), 51-104 (t. 1, p. 70). 
los poetas bernescos es evidente y ha dejado varios rastros en sus poemas. Recordemos los tercetos en alabanza de la pulga, de los cuernos, de la cola o de la zanahoria ${ }^{47}$. Todos ellos tienen antecedentes italianos muy claros. El primero imita y parafrasea el Capitolo del pulice de Ludovico Dolce, el segundo debió inspirarse en los tercetos en alabanza de los cuernos del Lasca o de Pietro Nelli, el tercero pudo tomar la idea de Le lodi della coda que forma parte de las Satire de Giovanni Agostino Caccia ${ }^{48}$, y el último se basó en los dos capítulos de elogio a las zanahorias de Mattio Franzesi.

La poesía bernesca dejó huellas en otros importantes poetas burlescos españoles. Baltasar del Alcázar imitó muy de cerca el soneto de Berni "Chiome d'argento fine, irte e attorte", parodia de Bembo y de la descriptio puellae propia de la poesia petrarquista. El soneto de Alcázar "Cabellos crespos, breves, cristalinos" sigue claramente el tema, la distribución y el léxico de los ver. sos italianos ${ }^{49}$. También uno de los sonetos atribuidos a Góngo ra donde se satiriza el matrimonio se inspiró en Berni: "Comeı salchichas y hallar sin gota". La enumeración de las penurias alimenticias y existenciales por las que pasa el casado imitan e soneto bernesco "Cancheri, e beccafichi magri arrosto" 50 .

Como puede verse, la mayoría de los textos donde se apre eia la influencia bernesca permanecieron manuscritos durant el Siglo de Oro. Las obras de burlas tardaron más que la poesía petrarquista en alcanzar su reconocimiento y pasar a la trans misión impresa. La influencia de la lírica bernesca se encuen tra, pues, a menudo en documentos no muy conocidos o poce estudiados. Un buen ejemplo de ello son las actas de la Acade

${ }^{4}$ A. González Palencia y E. Mele, Vida y obras de don Diego Hurtado de Mer doza, Instituto de Valencia de Don Juan, Madrid, 1941-1943, t. 3, p. 102: "D Berni y de los poetas bernescos derivó sus capítulos y sus sonetos burlesco Mendoza, que fue el primero en introducirlos en la poesía castellana". Lc tercetos a la pulga y a la cola se atribuyen en ocasiones también a Gutierr de Cetina.

48 Le satire, et capitoli piaceuoli, [Giovanni Antonio di Castiglione], Mil: no, 1549, núm. 21.

49 A. Martínez-Peñuela Vírseda, "La visión paródica del petrarquismo e Francesco Berni y en Baltasar del Alcázar", en Actas del IX Simposio de la Soci dad Española de Literatura General y Comparada, Universidad de Zaragoza-Bat co Zaragozano, Zaragoza, 1994, t. 2, pp. 189-196.

50 G. E. Bosurgi, "La caricatura della donna nel Berni e in due liri. spagnuoli del secolo xvi", en Studi in onore di Francesco Torraca, Società Ed trice Dante Alighieri, Napoli, 1922, pp. 433-443. 
mia de los Nocturnos, que funcionó en Valencia de 1591 a 1594. Entre los poemas de los académicos hay varios de clara inspiración bernesca: alabanzas a la locura, la enfermedad, la hormiga, el cuervo, la pulga, los perrillos de falda o el mosquito. Los elogios paradójicos se escriben en varios metros e incluso en prosa (y pueden ser también "en contra" de algo). Además, Berni es recordado explícitamente en el Discurso alabando la breva del académico Miedo (Francisco Tárrega):

Cogitanti mihi, illustres Académicos, que los caprichos, como dize el Bernia, vienen a despecho del hombre ${ }^{51}$.

El pasaje alude a los últimos versos del capítulo In lode dAristotele de Berni (Rime, 23, vv. 103-105): "Io non mi so scusar, se non con dire / Quel ch'io dissi di sopra: e' son capricci, / Ch'a mio dispetto mi voglion venire". Aunque la referencia pudo ser indirecta, ya que se parece mucho a las palabras con las que Antonio Blado (alias "Barbagrigia"), editor de la Ficheide, empieza su dedicatoria de la obra: "I Capricci (come disse il Bernia) vogliono venire agli uomini a lor dispetto" (p. 83). En cualquier caso, resulta muy significativo que Berni se cite como autoridad con tanta soltura. Eso demuestra una cierta familiaridad con la literatura burlesca italiana, que se refleja también en el conocimiento de la Ficheide de Annibal Caro que ya empleara Barahona de Soto.

La presencia de Berni y los bernescos como autoridad en la que apoyarse se halla también en la Respuesta herreriana a las Observaciones de Prete Jacopín (Juan Fernández de Velasco). Fernando de Herrera fue uno de los poetas cultos por excelencia del Siglo de Oro. Pero, pese a su formación humanística y a su erudición, no desdeñó la literatura burlesca italiana y se apoyó en ella para reforzar su ataque al condestable Fernández de Velasco que le había criticado por su edición de la obra de Garcilaso. Así como en las Anotaciones Herrera demostró conocer profundamente la tradición "alta" italiana (petrarquistas y épicos), que cita y compara con los poetas españoles, en su Respuesta da prueba de haber leído con detenimiento a los autores bernescos. De hecho, el texto del escritor andaluz se abre con una cita tomada del capítulo A fra Bastian del Piombo de Berni.

51 Actas de la Academia de los Nocturnos, eds. J. L. Canet, E. Rodríguez y J. L. Sirera, Edicions Alfons el Magnànim, Valencia, 1988, t. 1, p. 161. 
En total, Herrera cita siete veces los capitoli de Berni ( 5 poemas), tres veces los de Caporali ( 2 poemas) y dos veces los de Della Casa (1 poema). Entre tanta cita dejó también algún juicio aislado sobre Berni y su poesía. Herrera parece considerar la obra bernesca como un modelo maldiciente, pero muy ingenioso. Del poeta italiano dice que "es uno de los mas descarados Coplistas que á avido en todo el Paes de Arno, pero es bueno para los que dizen cosas grandes i nuevas como vos dezís"52. Berni y sus imitadores formaban parte de la base literaria herreriana, pero el autor la usó sólo en un contexto acorde a ella, como su polémica literaria contra Prete Jacopín. En Herrera se aprecia claramente esa fragmentación en dos grupos de la tradición poética italiana en España en el siglo xvi. Por una parte los petrarquistas y los épicos, alabados e imitados er obras que se publicaron durante todo el Siglo de Oro; por otrc los bernescos, que fueron también muy leídos, pero cuyas imi taciones circularon principalmente de forma manuscrita.

Por lo tanto, los autores italianos debieron constituir un mo delo importante para los poetas burlescos españoles. Sin embar go, para la definitiva consagración del género en España hay qu esperar el cambio estético y formal que se produjo en el Barroco Este proceso consiste, básicamente, en una dignificación que st aprecia en el paso de una circulación sobre todo manuscrita a un: impresa. La poesía jocosa, cada vez más, empieza a ocupar un pa pel destacado en los poemarios que se fueron publicando a lo laı go del siglo. La obra de Góngora supuso el primer paso hacia sı mayor consideración. Con la difusión de sus versos festivos en vé rias ediciones impresas a lo largo del xviI colaboró decididamer te a la canonización de la modalidad burlesca en el ámbito de 1 poesía culta. Hasta la segunda década del siglo todavía había existido serias vacilaciones en este sentido. Vicente Espinel recc gió sus Diversas rimas en 1591 y excluyó sistemáticamente de est colección sus versos festivos. Otro caso cercano es el de Dieg Hurtado de Mendoza. Su obra poética se reunió póstuma y se ed tó en 1610 a cargo de fray Juan Díaz Hidalgo, quien se negó tan bién a incluir las composiciones burlescas "por no contrauenir la grauedad de tan insigne Poeta"53. Pero con las primeras edici

\footnotetext{
52 En J. Montero, La controversia sobre las "Anotaciones" herrerianas, Ayu tamiento de Sevilla, Sevilla, 1987, p. 201.

53 Obras del insigne Cavallero Don Diego de Mendoza, Embaxador del Empe: dor Carlos Qvinto en Roma, Juan de la Cuesta, Madrid, 1610, f. Il 6v.
} 
nes de la obra gongorina, pese a sus problemas iniciales con la Inquisición, la lírica burlesca adquiere un grado de reconocimiento desconocido hasta el momento ${ }^{54}$.

Una prueba evidente del nuevo prestigio del que empieza a disfrutar la lírica burlesca se halla ya en la obra de Cervantes. En 1614 publica su Viaje del Parnaso que es imitación explícita de dos obras del bernesco Cesare Caporali: el Viaggio di Pamaso y los Avvisi di Pamaso ${ }^{55}$. La poesía burlesca empieza a aparecer en textos impresos.

Alonso de Castillo Solórzano publica en 1624 y 1625 las dos partes de sus Donaires del Parnaso, que contienen sólo versos jocosos, salvo alguno de elogio. En el poema que abre la obra, dedicado Al lector, indica que la función más destacada de esta obra es ofrecer una distracción a las mentes ocupadas: "por darle vacaciones al cuydado". Este objetivo se alcanza sobre todo gracias al empleo adecuado de las técnicas conceptistas, pues al hombre discreto: "la agudeza admira" 56.

En 1629 Jacinto Alonso Maluenda da a la estampa su Cozquilla del gusto, poemario de tipo exclusivamente burlesco. En los preliminares de la obra se justifica ante el público lector y reivindica la validez de su musa jocosa. Sus versos buscan el entretenimiento y a partir de este parámetro hay que juzgarlos:

solo te encargo que no mires con veras cuydadosas las descuydadas burlas que ensarta mi musa por darte gusto, que como estas aduertido de que le puedes dar nombre de jocosa ${ }^{57}$.

Maluenda vuelve a publicar una colección de versos y prosa de naturaleza semejante en 1631: el Bureo de las Musas del Turia. Nuevamente, defiende el valor de su obra de burlas ${ }^{58}$. Otro au-

54 De estas cuestiones se ocupa A. PÉrez Lasheras en sus libros Fustigat mores y Más a lo moderno.

55 Véanse, B. Croce, "Due illustrazioni al Viaje del Parnaso del Cervantes", en Homenaje a Menéndez y Pelayo en el año vigésimo de su profesorado. Estudios de erudición española, pról. J. Valera, Librería General de Victoriano Suárez, Madrid, 1899, t. 1, pp. 161-193; y las matizaciones de E. L. Rrvers, "Antecedentes genéricos del Viaje del Parnaso", en Dialogo. Studi in onore di Lore Terracini, ed. I. Pepe Sarno, Bulzoni, Roma, 1990, t. 2, pp. 575-582.

56 Donayres del Parnaso, Diego Flamenco, Madrid, 1624, f. II 7.

57 Cozquilla del gusto, ed. E. Juliá Martínez, CSIC, Madrid, 1951, p. 7.

58 Bureo de las Musas del Turia y Tropezón de la risa, ed. E. Juliá Martínez, CSIC, Madrid, 1951, p. 9: "esta pequeña obra, (a la qual di nombre de Bureo, por ser de donayres)". 
tor burlesco que da a luz sus composiciones en verso por esos años es Salvador Jacinto Polo de Medina. En 1630 aparece su colección titulada El buen humor de las Musas. En la dedicatoria se refiere a sus obras apodándolas "burlas" y, más adelante, les atribuye el mérito de proporcionar al lector un merecido recreo, como ya señalara Castillo Solórzano. Resuenan en estas palabras ecos de las teorías aristotélicas y de los tratados rena. centistas, cuales el De sermone o el Cortegiano. La risa cumple unc función útil dentro de la sociedad, es un complemento necesa rio para la vida del hombre:

Aun a las canas no les contradijera yo lo afable y entretenido, qur no es indecente la alegría y no dice prudencia lo feroz de un ros tro, no ha de ser todo lo rígido y lo grave de un ceño; descansa tiene lo entero en las materias de estado, no ha de estar tan enca recida la entereza en el gobierno, buscarse tiene algún ocio a lı prudencial $^{59}$.

En 1634, un grande del panorama literario como era Lop de Vega publica una colección de versos eminentemente bu lescos: las Rimas de Tomé de Burguillos. En estas rimas se parc dian el canon petrarquista y el de la épica, invirtiendo todos st tópicos en clave grotesca: lo alto se torna bajo y lo exquisito vu gar. Lope, siempre tan atento a las modas y los gustos del públ $\mathrm{co}$, se produce en un poemario festivo donde la diversión es $\mathrm{s}$ meta principal. No me parece, pues, que con este libro esté d mostrando su desencanto hacia la creación poética, como a $\mathrm{v}$ ees se ha dicho, sino más bien lo contrario ${ }^{60}$. El que realmen está desengañado no escribe y, desde luego, no publica sı obras. Se trata, en cambio, de un claro intento de Lope c mantener su fama, demostrando su capacidad de adaptarse molde burlesco que cada vez con más pujanza iba ocupanc un lugar privilegiado en el ámbito literario del Siglo de Oro. él se refiere claramente en uno de los sonetos que cierra el ca cionero petrarquista paródico, llamándolo "nuevo estilo"61. I

59 En Obras completas, ed. A. Valbuena Prat, Academia de Alfonso X Sabio, Murcia, 1948, p. 245.

60 Así lo entiende, por ejemplo, F. PEDRAzA, "El desengaño barroco las Rimas de Tomé de Burguillos", Anuario de Filología, 4 (1978), p. 400: "el ] pe de las Rimas de Tomé de Burguillos se retira de la acción".

${ }^{61}$ Rimas humanas y divinas del licenciado Tomé de Burguillos, ed. A. Car ño, Almar, Salamanca, 2002, 163, v. 4. 
las advertencias que encabezan el volumen, tal y como iba siendo habitual en este tipo de obras, Lope explica y defiende su "poesía faceciosa".

Otro acontecimiento importante para comprender el alcance de la poesía festiva es la Academia burlesca de 1637 que se organizó en honor del propio rey Felipe IV ${ }^{62}$. Se trata de un acto oficial y, pese a sus carácter jocoso, demuestra hasta qué punto estaba consolidada la literatura burlesca en el siglo XVII. Entre los participantes se cuentan autores de segunda fila, pero también otros de mayor renombre, sobre todo Vélez de Guevara que presidió la sesión, o el Príncipe de Esquilache y Francisco de Rioja que formaron parte del jurado.

En 1648 se publicó póstumo el Parnaso español de Francisco de Quevedo, que dedica un apartado a la poesía burlesca: la musa Talía. Se trata de la sección más voluminosa de toda la obra. Entre sus versos también es posible hallar varios poemas que tienen una deuda con la tradición bernesca. Pensemos, por ejemplo, en los sonetos $A$ un nariz o Al mosquito de la trompetilla. Son versos dedicados a cantar argumentos pedestres y vulgares, que aparecían también en las antologías de la lírica burlesca italiana ${ }^{63}$.

El proceso de consolidación de la poesía burlesca se va acentuando a medida que avanza el siglo. Recordemos el éxito de ventas de las obras de Anastasio Pantaleón de Ribera, poeta de academia y de poesías fundamentalmente intrascendentes y jocosas, que durante el xvII conocen cinco ediciones. El público gusta mucho de este tipo de composiciones, y los mercaderes de libros no pierden ocasión de sacar provecho de ello. Es muy representativa, a este respecto, la antología poética preparada por Josef Alfay en 1654. Las Poesias varias de grandes ingenios españoles permiten tomar el pulso a los gustos del público, llegados ya a mediados de siglo. Lo que refleja este libro es la preferencia evidente por dos modalidades: la poesía amorosa y la festiva. Nuevamente, el criterio ordenador ha respondido a una finalidad básica: la de proporcionar diversión y variedad.

\footnotetext{
62 Sobre esta academia véase J. Sánchez, Academias literarias del Siglo de Oro español, Gredos, Madrid, 1961, pp. 134154.

63 Para los elogios de narices descomunales en la poesía bernesca y su relación con el escritor español véase F. Plata, "Contribución al estudio de...", pp. 242-243. Me ocupo de la influencia de la tradición italiana en la poesía burlesca de Quevedo en mi libro La poesía burlesca de Quevedo y sus modelos italianos, Universidad, Santiago de Compostela, 2003.
} 
En el prólogo, Alfay insiste en ello: "Varias son las poesías que te ofrezco, lector amigo, pero el deseo de entretenerte con ellas es único" 64 .

Comparando el corpus de las Poesías varias con el de la más importante antología poética de principios de siglo, las Flores $d_{1}$ poetas ilustres (1605) recogidas por Pedro Espinosa, se confirmc el cambio de estética y de gustos literarios a partir de la segun da década del siglo xvir. En las Flores priman las poesías amoro sas, las morales y las religiosas. Lo burlesco ocupa un ámbitc bastante reducido, representado sobre todo por un soneto di Mateo Vázquez de Leca ("Cuerpo de Dios, Leandro enterneci do"), otro de Espinosa ("Rompe la niebla de una gruta escu ra"), unos epigramas de Baltasar del Alcázar y algunos poema de Quevedo. Frente a la contención y medida de gran parte d. las composiciones de las Flores, se hallan en la colección de A fay numerosos versos irreverentes basados a menudo en lo ir trascendente elevado a categoría poética.

Para comprender el éxito de la poesía burlesca es necesari estudiar el cambio de poética operado en el siglo XVII. Las pri ceptivas, desde el Medievo hasta el Renacimiento, entendían ] literatura como una combinación de dos elementos fundameI tales: el docere y el delectare. Por tanto, el sentido último de ur obra literaria dependía de su capacidad de proporcion: una enseñanza al lector por medio de palabras adecuadas. Si embargo, ya en el Renacimiento esta concepción empezó a c luirse y a dar, gradualmente, mayor cabida al factor puramen estético y al deleite. En España este proceso fue más lento q1 en Italia, debido también al fuerte conservadurismo de la $\mathrm{m}$ yoría de sus preceptistas ${ }^{65}$. Sin embargo, el ideal formal-hed nista se fue imponiendo en la concepción poética del Siglo ، Oro. La forma y la belleza empezaban a ser consideradas val res primarios para las obras literarias y, cada vez más, el enfre tamiento entre res y verba se va a ir decantando a favor de 1 segundas ${ }^{66}$. Paulatinamente, la retórica es asimilada a la elocu y los tratados dan mayor cabida al estudio del ornato verbal. $]$

64 Poesias varias de grandes ingenios españoles, ed. J. M. Blecua, Instituci "Fernando el Católico", Zaragoza, 1946, p. 5.

65 A. García Berrio, Formación de la Teoria literaria moderna (2). Teoria. tica del Siglo de Oro, Universidad, Murcia, 1980, p. 468.

${ }^{66}$ Sobre la polémica res-verba en el Siglo de Oro véase D. H. DARST, In tio. (Polémicas sobre la imitación en el Siglo de Oro), Orígenes, Madrid, IC pp. 51-82. 
hecho, en la Elocuencia española (1604) de Jiménez Patón se puede leer una sentencia tan clara como tajante al respecto: "La Rhetórica es un arte que enseña adornar la oración" 67.

El resultado más evidente de este proceso, por lo que se refiere a la literatura, es el triunfo del artificio y el ingenio, base de toda la teoría barroca. De aquí parte la teorización gracianesca sobre el conceptismo y las formas de la agudeza: "No se contenta el ingenio con sola la verdad, como elijuicio, sino que aspira a la hermosura" 68 . El concepto se define así como la capacidad de enlazar cosas dispares y distantes, provocando la sorpresa en el lector y dando muestra del ingenio del poeta.

Aunque las bases literarias del siglo xvi y del xvir descansan sobre una misma tradición retórica y poética, en el xvir se da prioridad a elementos que habían tenido menor cabida en el siglo anterior. Ya Aristóteles en su Retórica había destacado el placer que nace de la sorpresa y lo inesperado: "conviene hacer algo extraño el lenguaje corriente, dado que se admira lo que viene de lejos, y todo lo que causa admiración, causa asimismo placer"69. Los poetas barrocos hicieron suyas estas palabras y persiguieron en sus obras el deleite intelectual por medio de varios caminos. Los géneros festivos, en este sentido, gozaron de especial predicamento por su aptitud para la consecución de una literatura ingeniosa. En este contexto, Marcial fue considerado el poeta de la agudeza por antonomasia y los tratadistas del conceptismo como Gracián y Matteo Peregrini (Delle acutezze, 1639) lo citaron con gran profusión ${ }^{70}$. Tanto el ingenio como la risa descansan sobre un mismo elemento básico: la sorpresa. La "decepción" de las expectativas en el lector era considerada como una de las primeras causas del ridículo. Como en los epigramas de Marcial, lo que suscita la hilaridad es toparse con un final inesperado, que coge desprevenido al lector estableciendo una asociación sorprendente. Emanuele Tesauro, otro importante teórico del conceptismo, recoge estas ideas en su Cannochiale aristotelico:

${ }^{67}$ Elocuencia española en arte, ed. G. C. Marras, Anejo I de El Crotalón, Madrid, 1987, p. 67.

68 Agudeza y arte de ingenio, ed. E. Correa Calderón, Castalia, Madrid, 1988 , t. 1, p. 54.

${ }^{69}$ Retórica, trad. Q. Racionero, Gredos, Madrid, 1990, 1404b.

70 También Pontano le dedica un capítulo entero en su De sermone (III, 18). 
Egli è dunque vna segreta \& innata delitia dell'Intelletto humano, l'auuedersi di essere stato scherzeuolmente ingannato: peroche quel trapasso dell'inganno al disinganno, è vna maniera d'imparamento, per via non aspettata; \& perciò piaceuolissima... Di questa natura son tutti gli Scherzi giocosi; \& le burle innocentemente noceuoli, che nelle conuersationi ciuili, si van per gabbo facendo l'vno all'altro alla sproueduta ${ }^{71}$.

En este ámbito poético se inscribe, pues, la práctica de la poesía burlesca del Siglo de Oro. Esta modalidad se basa en la agudeza y búsqueda de la diversión a través de la sorpresa y el alarde intelectual. Se trata, en palabras de Alfay, de un "ingenioso entretenimiento de entendidos"72.

En la obra de Berni y de otros poetas burlescos italianos los escritores barrocos pudieron encontrar un valioso precedente para imitar en sus versos. La lírica bernesca se fundamenta er la experimentación lingüística y la búsqueda del concepto sor. prendente. La palabra y sus matices, el juego verbal, son algu nos de sus elementos constituyentes que trazan un puent entre la literatura renacentista y la barroca.

La poesía burlesca española del Siglo de Oro surge, pues del impulso histórico del Renacimiento y del importante pape que atribuyó a la risa y a la literatura de entretenimiento. A estc se añadió en el siglo xvir la estética conceptista que tuvo en la li rica jocosa un canal privilegiado para ejercitar el ingenio. Sc bre esta base teórica se desarrolló la poesía burlesca española que encontró en la tradición italiana una importante fuente d inspiración. Berni y sus imitadores repercutieron en autore del siglo Xvi como Diego Hurtado de Mendoza, Barahoua d Soto y el mismo Fernando de Herrera. En el siglo xvi la poesí burlesca se convirtió en uno de los géneros literarios más ex tosos y se enriqueció con nuevos estímulos y fuentes, entre la que ocupan un lugar destacado las italianas. Las antologías be: nescas constituyeron un corpus burlesco fundamental; varic autores del Siglo de Oro, que las leyeron e imitaron, sintetizaro

71 Il Cannochiale aristotelico, Gio. Sinibaldo, Torino, 1654, pp. 551-552. : en las retóricas clásicas la risa puede ser entendida como resultado de la sc presa: Áristóteles, Retónica, 1412a; Cicerón, Dé oratore, II, 255 y 281-29 Quintuliano, Institutio Oratoria, VI, 3, 24 y 84. La idea pasó a las preceptiv del Renacimiento y del Barroco.

${ }^{79}$ Poesias varias, p. 4. 
en sus versos jocosos algunos de los principios básicos del conceptismo. Pues, como señaló Quevedo, "Lo ridículo, todo consta de ingenio"73.

Rodrigo Cacho Casal Universidad de Santiago de Compostela

${ }^{73}$ En L. López Grigera, Anotaciones de Quevedo a la "Retórica" de Aristóteles, Gráficas Cervantes, Salamanca, 1998, p. 166. 
